\title{
The Use of Dispersed Catalysts in Catalytic Steam Cracking of Heavy Oil
}

\author{
Anastasia V. Saiko ${ }^{a}$, Olesya O. Zaikina ${ }^{a, b}$, \\ Gleb A. Sosnin ${ }^{* a, b}$, Peter M. Yeletsky ${ }^{a}$, \\ Yuliya K. Gulyaeva, a, , Oleg V. Klimova, \\ Aleksander S. Noskov and Vadim A. Yakovleva, ${ }^{\mathrm{a}}$ \\ ${ }^{a}$ Boreskov Institute of Catalysis SB RAS \\ 5 Akademika Lavrentieva, Novosibirsk, 630090, Russia \\ ${ }^{b}$ Novosibirsk State University \\ 1 Pirogova Str., Novosibirsk, 630090, Russia
}

Received 02.09.2019, received in revised form 08.10.2019, accepted 10.11.2019

In this paper the influence of dispersed catalysts obtained in situ based on various metals (Mo, $\mathrm{Ni}, \mathrm{Fe}$, Co) has been studied on the yield and properties of liquid products in a slurry-reactorat a temperature of $425{ }^{\circ} \mathrm{C}$ and a pressure of $20 \mathrm{MPa}$. The most active catalytic compositions for the process of catalytic steam cracking of oil (Mo and Mo-Fe) were selected. In the presence of dispersed Mo and Mo-Fe catalysts the samples of the semisynthetic oils were produced. In the rectification process the gasoline, diesel, oil and residual fractions were allocated. The selected fractions were analyzed by physicochemical methods for a wide range of performance in comparison with the initial heavy oil. The efficiency of Mo-Fe catalysts for obtaining semisynthetic oil with an increased content of light fractions (i.b.p. $-360^{\circ} \mathrm{C}$ ) during the catalytic steam cracking of heavy oil was shown.

Keywords: heavy petroleum feedstocks, semisynthetic oil, dispersed catalyst, steam cracking, slurryreactor.

Citation: Saiko A.V., Zaikina O.O., Sosnin G.A., Yeletsky P.M., Gulyaeva Yu.K., Klimov O.V., Noskov A.S., Yakovlev V.A. The use of dispersed catalysts in catalytic steam cracking of heavy oil, J. Sib. Fed. Univ. Chem., 2019, 12(4), 562-572. DOI: $10.17516 / 1998-2836-0151$.

(c) Siberian Federal University. All rights reserved

* Corresponding author E-mail address: sosningleb@catalysis.ru 


\title{
Использование дисперсных катализаторов \\ В процессе каталитического \\ парового крекинга тяжелой нефти
}

\author{
А.В. Сайко ${ }^{a}$, O.О. Заикина ${ }^{a, \tilde{\sigma}}$, \\ Г.А. Соснин ${ }^{\text {a, }}$, П.М. Елецкий ${ }^{\mathrm{a}}$, Ю.К. Гуляева ${ }^{\mathrm{a}, \tilde{\sigma}}$, \\ О.В. Климов ${ }^{\text {a }, ~ А . С . ~ Н о с к о в ~}{ }^{\mathrm{a}}$, В.А. Яковлев ${ }^{\mathrm{a}, \boldsymbol{\sigma}}$ \\ ${ }^{a}$ Институт катализа им. Г.К. Борескова СО РАН \\ Россия, 630090, Новосибирск, пр. Академика Лаврентьева, 5 \\ ${ }^{\sigma}$ Новосибирский государственный университет \\ Россия, 630090, Новосибирск, Пирогова, 1
}

\begin{abstract}
В данной работе изучено влияние дисперсных катализаторов, полученных in situ, на основе различных металлов (Mo, $\mathrm{Ni}, \mathrm{Fe}, \mathrm{Co}$ ) на выход и свойства жидких продуктов облагоражсивания нефти в реакторе типа сларри при температуре $425{ }^{\circ} \mathrm{C}$ и давлении 20 МПа. Катализаторы были получены в режиме in situ эмульсионным методом. Выбраны наиболее активные каталитические композиции для процесса каталитического парового крекинга нефти (Mo и Mo-Fe). В присутствии дисперсных Мо- и Мо-Fе-катализаторов были наработаны образиы полусинтетических нефтей, проведена их ректификаиия и получены нефтяные фракции: бензиновая, дизельная, масляная и остаточная. Выделенные легкие фракции были проанализированы физико-химическими методами на широкий ряд эксплуатационных характеристик в сравнении с исходной тяжелой нефтью. Показана эффективность использования Mo-Fe-катализаторов для получения полусинтетической нефти с увеличенным содержанием светлых фракиий (н.к. $\left.-360^{\circ} \mathrm{C}\right)$ в проиессе каталитического парового крекинга тяжелой нефти.
\end{abstract}

Ключевые слова: тяжелое нефтяное сырье, полусинтетическая нефть, дисперсный катализатор, паровой крекинг, сларри-реактор.

\section{Введение}

В настоящее время активно развиваются подходы, основанные на термокаталитических превращениях тяжелого нефтяного сырья (ТНС) с использованием воды [1]. Основной целью разрабатываемых каталитических процессов облагораживания ТНС, в том числе и парового крекинга, является получение маловязкого жидкого продукта с высоким выходом ценных светлых фракций. В связи с физико-химическими особенностями перерабатываемого сырья, а именно высокой вязкостью и содержанием высокомолекулярных компонентов, в разрабатываемых процессах исследователи активно используют дисперсные катализаторы на основе различных металлов [2]. В зависимости от типа предшественника их разделяют на водорастворимые с образованием активной фазы in situ из обратных эмульсий, нефтерастворимые $[3,4]$ и ex situ порошковые катализаторы [5].

$$
-563-
$$


Для эффективного проведения процесса каталитического парового крекинга (КПК) необходимо использовать катализаторы, позволяющие интенсифицировать реакции крекинга, гидрирования, гидрогенолиза, деструкции C-C-, C-S-, C-N- и других связей, проявляющие низкую склонность к образованию продуктов уплотнения. В поисковой работе [6] были получены предварительные данные о возможности применения Fe- и Mo-Fe-содержащих дисперсных катализаторов в реакторе проточного типа. На основании полученных результатов был сделан вывод о необходимости оптимизации условий проведения КПК, ректификационного разделения полученных ПСН и детального анализа выделенных нефтяных фракций для выявления физико-химических особенностей протекания процесса облагораживания тяжелой нефти.

Цель данной работы - изучение влияния дисперсных катализаторов на основе различных металлов ( $\mathrm{Mo}, \mathrm{Ni}, \mathrm{Fe}, \mathrm{Co})$ на выход и свойства жидких продуктов облагораживания тяжелой нефти в сларри-реакторе (при $425^{\circ} \mathrm{C}$ и давлении 20 МПа) и выбор каталитической композиции, позволяющей получить полусинтетическую нефть с наибольшим содержанием светлых фракций. На основании результатов исследования качества светлых фракций необходимо оценить возможность их дальнейшего использования для получения компонентов моторных топлив.

\section{Экспериментальная часть}

\section{Свойства используемой нефти}

В работе использовали высокосернистую тяжелую нефть, добытую в Республике Татар-

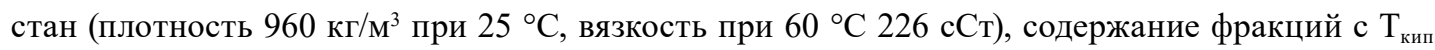
$>500{ }^{\circ} \mathrm{C} 48$ мас. \%, содержание серы 4,3 мас. \%, соотношение $\left.\mathrm{H}: \mathrm{C}=1,74\right)$.

\section{Методика приготовления катализаторов}

Обратную эмульсию готовили путем диспергирования водного раствора соли предшественника металла в тяжелой нефти при температуре $80{ }^{\circ} \mathrm{C}$. В качестве металлсодержащих предшественников использовали следующие соли: $\left(\mathrm{NH}_{4}\right)_{6} \mathrm{Mo}_{7} \mathrm{O}_{24}, \mathrm{Ni}\left(\mathrm{NO}_{3}\right)_{2}, \mathrm{CoCl}_{2}, \mathrm{FeSO}_{4}$. Диспергирование осуществляли с применением диспергатора IKA T-25 basic ULTRA-TURRAX при скорости перемешивания 24000 об/мин в течение 3 мин.

\section{Методика проведения экспериментов}

по каталитическому паровому крекингу

Исследование КПК тяжелой нефти проводили на установке с проточным реактором типа сларри при температуре $425^{\circ} \mathrm{C}$, давлении 2,0 МПа. Подачу обратной осуществляли с помощью подогреваемого до $60^{\circ} \mathrm{C}$ поршня со скоростью 100 мл/ч. Для поддержания давления в системе в реактор подавали аргон со скоростью 100 мл/мин.

Содержание cеры, азота и соотношение H:C исходной тяжелой нефти и продуктов ее переработки определяли на CHNS-O-анализаторе VARIOE LCUBE (Elementar Analysen systeme).

Фракционный состав выявляли методом имитированной дистилляции на газовом хроматографе Agilent 7890B по ASTM D7169 для исходной тяжелой нефти, полусинтетической нефти и по ASTM D2887 для выделенных светлых фракций (н.к. $-360{ }^{\circ} \mathrm{C}$ ). В качестве стандартного вещества для определения степени извлечения использовали вакуумный газойль. 
Плотность и кинематическую вязкость исходной тяжелой нефти и продуктов ее переработки измеряли на вискозиметре Штабингера по стандарту ASTM D7042.

Коксуемость исходной тяжелой нефти и полусинтетической нефти проводили методом Конрадсона в соответствии с ГОСТ 19932-99.

Групповой состав исходной тяжелой нефти и полусинтетической нефти устанавливали в соответствии с ГОСТ 11868-66 адсорбционно-хроматографическим методом после выделения асфальтенов в н-гексане с использованием аппарата Сокслета.

Содержание металлов в исходной тяжелой нефти и продуктах ее переработки выявляли на рентгенофлуоресцентном спектрометре ARL Perform'X.

Содержание ароматических углеводородовв дизельных фракциях определяли на ВЭЖХхроматографе Agilent 1260 Infinity по ASTMD6591. Для идентификации алифатических соединений использовали метод двумерной газовой хроматографии Agilent 7890A.

Групповой состав и октановое число (OЧ) бензиновых фракций выявляли методом капиллярной газовой хроматографии в соответствии с ГОСТ Р 52714-2007. Цетановый индекс (ЦИ) дизельных фракций определяли расчетным методом по ASTMD473.

Содержание олефинов в бензиновых и дизельных фракциях устанавливали методом йодных чисел в соответствии с ГОСТ 2070-82.

Температуру застывания дизельных фракций определяли с использованием аппарата ЛАЗ-М в соответствии с ГОСТ 20287-91.

Ректификаиию исходной тяжелой нефти и полусинтетических нефтей проводили последовательно с помощью установки, соответствующей по техническим характеристикам стандартизированному аппарату АРН-2 по ГОСТ 11011-85.

\section{Результаты и обсуждение}

В результате проведения экспериментов по КПК тяжелой нефти (ТН) в сларри-реакторе (температура $425{ }^{\circ} \mathrm{C}$, давление 2,0 МПа, содержание металлов 0,25 - 0,5 мас. \%, соотношение вода : нефть $=0,1: 1$, время контакта 1 ч) были получены данные о влиянии состава каталитических систем на выход и свойства полусинтетических нефтей. Оценку эффективности дисперсных катализаторов в изучаемом процессе проводили по совокупности параметров, отраженных в табл. 1.

В случае Мо-содержащего дисперсного катализатора наблюдается максимальный выход ПСН (88,5 мас. \%) с выходом светлых фракций 45,7 мас. \% и содержанием серы 3,3 мас. \%. При этом происходит уменьшение вязкости, плотности и увеличение конверсии углеводородов $\mathrm{C}_{500+}(46,8$ мас. \%).

Из данных табл. 1 видно, что в присутствии Ni-содержащих катализаторов процесс десульфидирования проходит на схожую с молибденом глубину (приблизительно на 23 \%). При использовании никеля наблюдается наибольший вклад процессов коксообразования $(9,8$ мас. \%) по сравнению с КПК в присутствии Мо-содержащего дисперсного катализатора (4,2 мас. \%). Склонность никеля к коксообразованию в процессе КПК приводит к снижению других показателей процесса, в том числе выхода светлых фракций (39,0 мас. \%). Подобные закономерности при облагораживании ТНС в присутствии никеля обсуждены ранее при исследовании КПК гудрона в сларри-реакторе и тяжелой нефти в статическом режиме [6, 7]. Таким образом, харак- 
Таблица 1. Выход и состав продуктов каталитического парового крекинга тяжелой нефти в присутствии различных дисперсных катализаторов на основе $\mathrm{Mo}, \mathrm{Ni}, \mathrm{Fe}, \mathrm{Co}$

Table 1. Yield and composition of products of catalytic steam cracking of heavy oil in the presence various dispersed catalysts based on $\mathrm{Mo}, \mathrm{Ni}, \mathrm{Fe}, \mathrm{Co}$

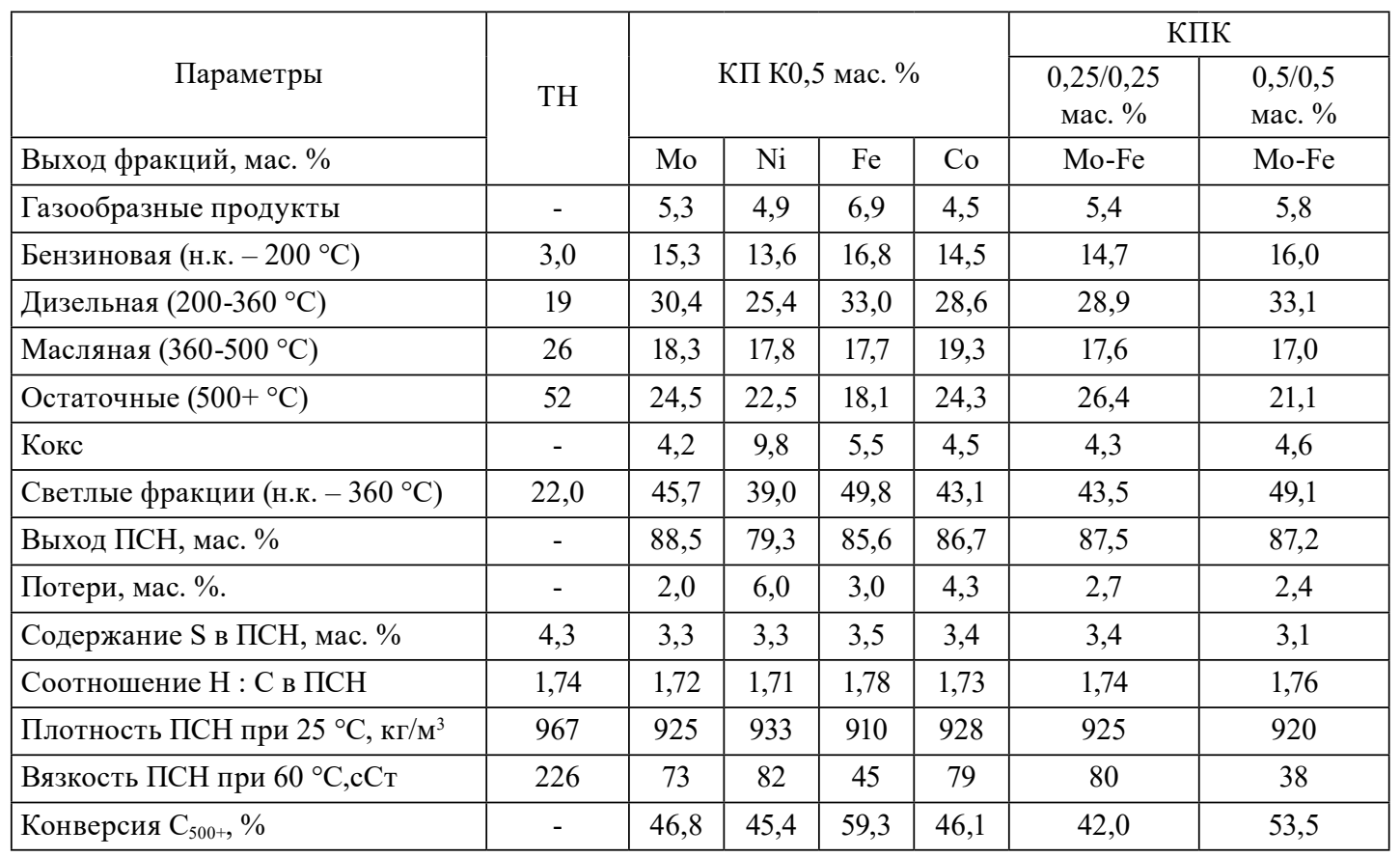

тер протекающих процессов на $\mathrm{Ni}$-содержащих катализаторах не зависит от режима проведения процесса, ввиду вышеуказанных особенностей Мо-содержащие системы являются более предпочтительными в облагораживании ТНС [8].

Использование $\mathrm{Fe}$-содержащего дисперсного катализатора позволяет увеличить выход светлых фракций (49,8 мас. \%) по сравнению с Мо-содержащим катализатором. Данный эффект связан, вероятно, с окислительно-восстановительным типом облагораживания ТНС [9]. При этом наблюдается увеличение выхода кокса и конверсии высококипящих фракций (59,3 \%), однако по сравнению с Мо степень обессеривания отличается незначительно.

Было обнаружено, что в присутствии Со можно получать ПСН с содержанием серы 3,4 мас. \% с выходом светлых фракций ниже на 2,6 \%, чем при использовании Мо.

Можно заключить, что наиболее подходящей каталитической системой для облагораживания ТН в изучаемых условиях $\left(425^{\circ} \mathrm{C}, 20\right.$ атм) является сочетание гидрирующего, обессеривающего (Мo) [8] и крекирующего ( $\mathrm{Fe})$ компонентов.

Показано, что в присутствии 0,25/0,25 мас. \% Мо и $\mathrm{Fe}$ выход светлых фракций равен 43,5 мас. \% с одновременным снижением содержания серы в ПСН до 3,4 мас. \%, с выходом 87,5 мас. \% и низком коксообразовании 4,3 мас. \%. Использование 0,5/0,5 мас. \% Mo- и $\mathrm{Fe}-$ содержащей системы приводит к суммарному эффекту, т.е. к увеличению выхода светлых фракций (до 49,1 мас. \%) с одновременным снижением содержания серы (до 3,1 мас. \%) при практически одинаковом выходе ПСН (87,2 мас. \%) и 4,6 мас. \% выходе кокса. Можно предпо- 
ложить, что в используемом мультикомпонентном дисперсном катализаторе Мо и Fе ответственны за превращения тяжелой нефти, характерные для монометаллических систем. Так, предположительно фаза $\mathrm{MoO}_{2}$ является активной в реакциях крекинга углеводородов в присутствии воды, в то же время $\mathrm{MoS}_{2}$ выступает в роли гидрирующей и десульфидирующей компоненты, а $\mathrm{FeO}_{\text {х }}$ фазы увеличивают выход светлых фракций, вероятно, благодаря окислительновосстановительному механизму [6].

Таким образом, по совокупности показателей КПК тяжелой нефти в сларри-ректоре при температуре $425{ }^{\circ} \mathrm{C}$ и давлении 2,0 МПа целесообразным является использование 0,5 мас. \% $\mathrm{Mo}-0,5$ мас. \% Fе дисперсной каталитической системы.

Для полусинтетических нефтей, полученных в процессе КПК тяжелой нефти в присутствии Мо- и Мо-Fе-дисперсных катализаторов, при оценке их углеводородного потенциала были определены следующие параметры: содержание металлов, коксуемость по Конрадсону и групповой состав. При использовании дисперсных катализаторов наблюдается снижение коксуемости по Конрадсону (с 9,7 до 7,4-7,9 мас. \%) и содержания ванадия (с 200 до 54-63 ppm) и никеля (с 60 до 29-37 ppm).

Сравнение группового состава (рис. 1) показало, что использование катализаторов позволяет снизить содержание бензольных (до 6,9 мас. \%) и спирто-бензольных (до 5,2 мас. \%) смол при увеличении содержания насыщенных углеводородов (с 25 до 37-39 мас. \%), практически неизменном содержании ароматических соединений (40-43 мас. \%) и незначительном увеличении асфальтенов (с 6,4 до 8,0-8,3 мас. \%), что, вероятнее всего, связано с гидрирующей способностью используемых катализаторов. Снижение вязкости и плотности ПСН по сравнению с исходной ТН коррелирует со смещением фракционного состава в более низкотемпературную область. В процессе КПК происходит значительное увеличение содержания насыщенных углеводородов при несущественном увеличении ароматических УВ с ростом количества ас-

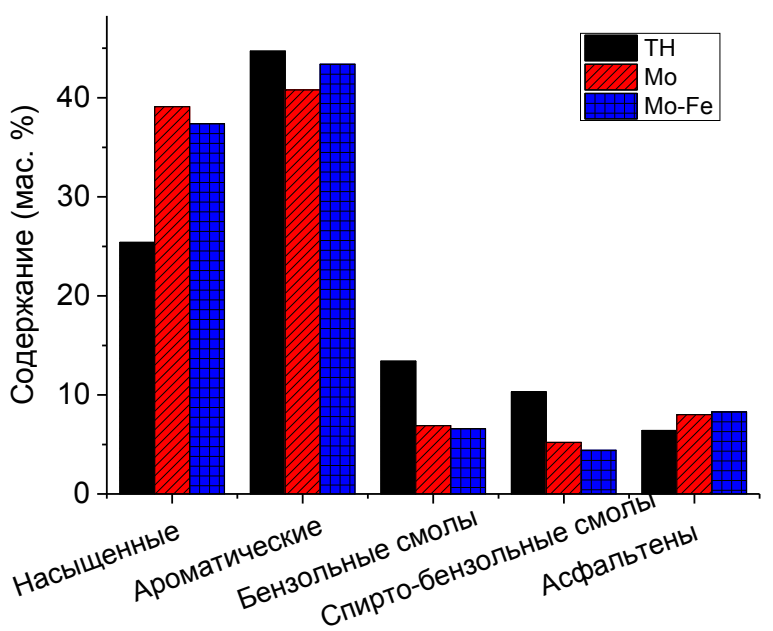

Рис. 1. Групповой состав исходной тяжелой нефти и полусинтетических нефтей, полученных в ходе каталитического парового крекинга тяжелой нефти в присутствии Мо- и Мо-Fе-дисперсных катализаторов

Fig. 1. The group composition of the initial heavy oil and semisynthetic oils obtained during the catalytic steam cracking of heavy oil in the presence of Mo- and Mo-Fe dispersed catalysts

$$
-567-
$$


фальтенов и снижением содержания смолистых компонент (рис. 1). Наблюдаемое изменение группового состава можно объяснить деструкцией смол с образованием парафино-нафтеновых углеводородов, перераспределением водорода, а также рекомбинацией образующихся свободных радикалов, интенсификацией процессов конденсации высокомолекулярных УВ и др. [8, 10]. Такие условия процесса, с одной стороны, позволяют получать облагороженный жидкий продукт с меньшим содержанием асфальтенов, но с другой - не обеспечивают его высокого выхода и не приводят к значительному увеличению доли ценных светлых фракций в отсутствие дополнительного донора водорода [1].

Полусинтетические нефти, полученные в процессе КПК крекинга в присутствии Мо- и Mo-Fe-содержащих дисперсных катализаторов, а также исходная тяжелая нефть были разделены на отдельные фракции в процессе ректификации. Бензиновые и дизельные фракции, полученные после выделения, были проанализированы физико-химическими методами на ряд эксплуатационных характеристик, позволяющих оценить качество светлых фракций.

Исследование группового состава бензиновых фракций показало существенные различия в содержании основных групп углеводородов (рис. $2 A$ ). Так, при использовании дисперсных катализаторов было отмечено увеличение содержания парафинов (с 3,3 до 8,1-8,2 мас. \%) и ароматических соединений (с 32 до 48-50 мас. \%) при снижении содержания изопарафинов (с 39 до 27-29 мас. \%) и нафтенов (с 17,3 до 9,2-10,5 мас. \%) по сравнению с исходной бензиновой фракцией. В процессе КПК происходит снижение содержания олефинов в бензиновых фракциях (с 2,3 до 1,2-2,0 мас. \%).

Было обнаружено, что ОЧ по исследовательскому методу всех трех бензиновых фракций имеют сходные величины (84-85), возможно, это связано с компенсационным эффектом ОЧ углеводородными компонентами. В процессе КПК интенсивно протекают реакции крекинга и гидрирования с получением высокой доли парафинов в составе бензиновых фракций, а также реакции перераспределения водорода, приводящие к увеличению арома-
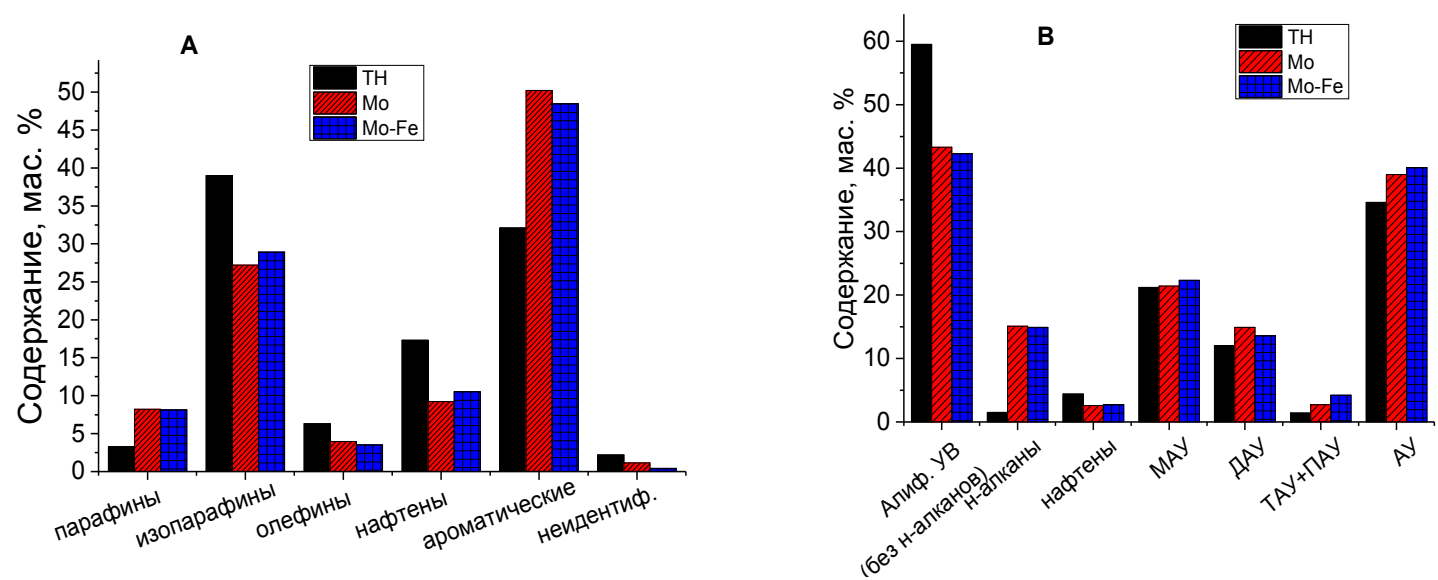

Рис. 2. Групповой состав бензиновых (А) и дизельных (В) фракций, полученных из полусинтетических нефтей с Мо- и Мо-Fе дисперсными катализаторами и из исходной нефти

Fig. 2. The group composition of gasoline (A) and diesel (B) fractions obtained from semisynthetic oils with Moand Mo-Fedispersed catalysts and from the original oil 
Таблица 2. Характеристики бензиновых и дизельных фракций, полученных из полусинтетических нефтей с Мо- и Мо-Fe-дисперсными катализаторами и исходной нефти

Table 2. Characteristics of gasoline and diesel fractions obtained from semisynthetic oils with Mo- and Mo-Fe dispersed catalysts and the initial oil

\begin{tabular}{|c|c|c|c|c|c|c|}
\hline \multirow{3}{*}{ Параметры } & \multicolumn{3}{|c|}{ БФ } & \multicolumn{3}{|c|}{ ДФ } \\
\hline & \multirow{2}{*}{ Нефть } & \multicolumn{2}{|c|}{$\Pi \mathrm{\Pi CH}$} & \multirow{2}{*}{ Нефть } & \multicolumn{2}{|c|}{$\Pi \mathrm{CH}$} \\
\hline & & Mo & Mo-Fe & & Mo & Mo-Fe \\
\hline Плотность при $15^{\circ} \mathrm{C}$, кг/м ${ }^{3}$ & 796 & 812 & 817 & 889 & 901 & 905 \\
\hline Кинематическая вязкость при $15^{\circ} \mathrm{C}, \mathrm{cC}$ т & 1,3 & 1,4 & 1,5 & 10,6 & 11,4 & 14,2 \\
\hline Содержание серы, мас. \% & 0,5 & 1,5 & 2,5 & 2,5 & 3,2 & 3,6 \\
\hline Содержание азота, мас. \% & 0,3 & 0,01 & 0,02 & 0,7 & 0,1 & 0,1 \\
\hline Содержание олефинов, мас. \% & 2,3 & 1,2 & 2,0 & 0,9 & 0,4 & 0,2 \\
\hline $\mathrm{OЧ}_{\text {Им }} / Ц И$ & 84 & 85 & 84 & 38,1 & 35,9 & 32,9 \\
\hline
\end{tabular}

тических углеводородов. При этом плотность и вязкость бензиновых фракций, полученных с участием катализаторов, возрастает, что согласуется с изменением состава бензиновых фракций (табл. 2).

Для дизельных фракций, полученных из тяжелой нефти после КПК в присутствии Мо- и Mo-Fe-содержащего дисперсного катализатора, также наблюдаются более высокие показатели вязкости и плотности по сравнению с исходной дизельной фракцией (табл. 2). При исследовании группового состава дизельных фракций после КПК было отмечено снижение содержания изоалканов (с 59 до 42-43 мас. \%) с одновременным увеличением содержания н-алканов (с 1,5 до 14,9-15,1мас. \%), незначительным падением содержания нафтенов (с 4,4 до 2,6-2,7 мас. \%) и увеличением содержания ароматических соединений (с 35 до 39-40 мас. \%) по сравнению с исходной дизельной фракцией (рис. $2 B$ ). Для бензиновых и дизельных фракций отмечено увеличение содержания серы в сравнении с исходной тяжелой нефтью (табл. 2). Данный эффект известен и связан с перераспределением между фракциями серосодержащих соединений различного строения и температурами их кипения, а также выходом дистиллятных фракций.

Таким образом, можно предположить, что используемый тип катализаторов, как и в случае бензиновых фракций, является более селективным в получении н-алканов и соединений, содержащих ароматическую группу. Однако также стоит отметить снижение содержания олефинов (с 0,9 до 0,2-0,4 мас. \%) в случае использования дисперсных каталитических систем. Подобные изменения группового состава дизельных фракций, полученных с использованием Mo- и Mo-Fe-содержащих дисперсных катализаторов, обуславливают увеличение температуры замерзания (с минус 66 до минус 28 и минус $18{ }^{\circ} \mathrm{C}$ ) и падение цетанового индекса (с 38,1 до 32,9). В дизельных фракциях н-парафины влияют на эксплуатационные свойства: с одной стороны, обеспечивают необходимое значение цетанового индекса, а с другой - ухудшают низкотемпературные свойства, например температуру застывания $\left(\mathrm{T}_{3}\right)[11,12]$. Так, для исходной дизельной фракции наблюдается низкая $\mathrm{T}_{3}$ (минус $66^{\circ} \mathrm{C}$ ), что обусловлено низким содержанием н-алканов (1,5 мас. \%). При этом расчетное значение цетанового индекса равно 38,1 . Данный показатель определяется в исследуемой фракции содержанием изоалканов (59 мас. \%) и арома-

$$
-569-
$$


тических УВ (35 мас. \%). Полученные в процессе КПК дизельные фракции характеризуются повышенным содержанием н-парафинов (14,9-15,1 мас. \%) и ароматических УВ до 40 мас. \% и меньшим количеством изоалканов (43 мас. \%), содержание нафтенов меняется незначительно, что приводит к увеличению $\mathrm{T}_{3}$, падению цетанового индекса (32,9 пункта), а также увеличению вязкости и плотности. Изменение группового состава коррелирует с плотностью дизельных фракций, что может быть объяснено гидрирующей способностью катализаторов. Необходимо отметить, что полученные в процессе КПК дизельные фракции с данным групповым составом обладают большим потенциалом при дальнейшей переработке и компаундировании с получением товарных дизельных топлив. Эти бензиновые фракции также могут быть вовлечены во вторичные процессы получения компонентов моторных топлив.

Таким образом, изучение процесса КПК ТН в проточном сларри-реакторе позволило установить основные физико-химические закономерности протекания данного процесса. Снижение содержания серы в продуктах облагораживания достигается путем каталитического обессеривания с образованием серосодержащих газообразных продуктов (преимущественно сероводород) $[6,8]$. При этом содержание серы возрастает с увеличением температуры кипения нефтяных фракций. Содержание азота в полусинтетических нефтях, полученных в процессе облагораживания, ниже его значений в исходной нефти.

\section{Заключение}

Изучены особенности каталитического парового крекинга тяжелой нефти при $425^{\circ} \mathrm{C}$ и давлении 2,0 МПа в присутствии дисперсных катализаторов на основе различных металлов (Мо, $\mathrm{Ni}, \mathrm{Fe}, \mathrm{Co}$ ). По совокупности параметров наиболее перспективными для получения полусинтетической нефти с высоким содержанием светлых фракций являются дисперсные катализаторы на основе Мо и Mo-Fe (45,7 и 49,1 мас. \% соответственно). Полученные полусинтетические нефти характеризуются гораздо меньшими значениями вязкости (38-73 сСт) и плотности (920-

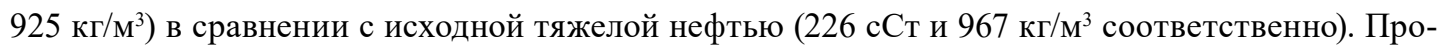
исходит снижение содержания серы в полусинтетической нефти с 4,3 до 3, 1 мас. \%. При исследовании группового состава обнаружено, что проведение процесса каталитического парового крекинга приводит к увеличению насыщенных и снижению смолистых компонентов, а также незначительному увеличению асфальтенов в жидких продуктах, что связано, по-видимому, с гидрирующей способностью используемых Мо- и Мo-Fe-дисперсных катализаторов. Было показано, что бензиновые фракции, полученные в процессе каталитического парового крекинга

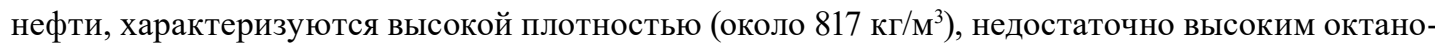
вым числом (84 по ИМ), а также высоким содержанием серы (1,5-2,5 мас. \%), ароматических УВ различного строения (40-50 мас. \%) и олефинов (1-2 мас. \%), а также недостаточным количеством изопарафинов ( 28 мас. \%). Дизельные фракции, полученные в процессе каталитического парового крекинга нефти, характеризуются высокой плотностью (около 905 кг/м ${ }^{3}$ ) вследствие высокого содержания высококипящих УВ, недостаточно высоким цетановым индексом (33-36), а также содержанием серы (3,2-3,6 мас. \%), ароматических УВ различного строения (МАУ 22 мас. \%, ДАУ 14 мас. \%, ТАУ 4 мас. \%).

Итак, показана перспективность использования Мо-Fе-катализаторов для получения полусинтетической нефти с увеличенным содержанием светлых фракций в процессе каталитиче- 
ского парового крекинга тяжелой нефти. Можно заключить, что для дальнейшего вовлечения данных светлых фракций в инфраструктуру вторичных процессов нефтепереработки требуется предварительное гидрооблагораживание с целью улучшения их эксплуатационных характеристик, что в конечном итоге позволит расширить сырьевую базу для получения компонентов моторных топлив.

\section{Благодарности}

Работа выполнена при финансовой поддержке Министерства науки и высшего образования Российской Федерации: соглашение № 14.607.21.0172, идентификационный номер соглашения RFMEFI60717X0172.

\section{Список литературы}

1. Eletskii P.M., Mironenko O.O., Kukushkin R.G., Sosnin G.A., Yakovlev V.A. Catalytic Steam Cracking of Heavy Oil Feedstocks: A Review. Catalysis in Industry 2018. Vol. 10(3), P. $185-201$.

2. Angeles M.J., Leyva C., Ancheyta J., Ramírez S.A Review of Experimental Procedures for Heavy Oil Hydrocracking with Dispersed Catalyst. Catalysis Today 2014. Vol. 220-222, P. 274-294.

3. Clark P.D., Kirk M.J. Studies on the Upgrading of Bituminous Oils with Water and Transition Metal Catalysts. Energy and Fuels 1994. Vol. 8(2), P. 380-387.

4. Khadzhiev S.N., Kadiev K.M., Kadieva M.K. Synthesis and Properties of Nanosized Systems as Efficient Catalysts for Hydroconversion of Heavy Petroleum Feedstock. Petroleum Chemistry 2014. Vol. 54(5), P. 323-346.

5. Морозов М.А., Акимов А.С., Журавков С.П., Золотухина Н.Ю., Свириденко Н.Н., Головко А.К., Восмериков А.В., Федущак Т.А. Каталитические свойства порошков карбида вольфрама в процессе крекинга тяжелого углеводородного сырья. Известия Томского политехнического университета. Инжиниринг георесурсов. 2017. Vol. 328(8), P. 16-24. [Morozov M.A., Akimov A.S., Zhuravkov S.P., Zolotukhina N.Yu., Sviridenko N.N., Golovko, A.K., Vosmerikov A.V., Fedushchak T.A. Catalytic properties of tungsten carbide powders in cracking heavy petroleum feedstock. Bulletin of the Tomsk Polytechnic University. Geo Assets Engineering 2017. Vol. 328(8), P. 16-24. (InRuss.)]

6. Kukushkin R.G., Eletskii P.M., Zaikina O.O., Sosnin G.A., Bulavchenko O.A., Yakovlev V.A. Studying the Steam Cracking of Heavy Oil over Iron- and Molybdenum-Containing Dispersed Catalysts in a Flow-Type Reactor. Catalysis in Industry 2018. Vol. 10(4), P. 344-352.

7. Соснин Г.А., Ларичев Ю.В., Елецкий П.М., Заикина О.О., Кукушкин Р.Г., Герасимов Е.Ю., Яковлев В.А. Исследование генезиса Ni- и Мо-содержащих суспендированных катализаторов парового крекинга тяжелой нефти. Журнал Сибирского федерального университета. Химия 2017. Vol. 10(4), P.489-501.[Sosnin G.A., Larichev Y.V., Eletskii P.M., Zaikina O.O., Kukushkin R.G., Gerasimov E.Yu., Yakovlev V.A. Genesis investigation of Ni and Mo-based dispersed catalysts of steam cracking of heavy oil. Journal of Siberian Federal University. Chemistry 2017. Vol. 10(4), P.489-501. (In Russ.)]

8. Mironenko O.O., Sosnin G.A., Eletskii P.M., Gulyaeva Y.K., Bulavchenko O.A., Stonkus O.A., Rodina V.O., Yakovlev V.A. A Study of the Catalytic Steam Cracking of Heavy Crude Oil in the 
Presence of a Dispersed Molybdenum-Containing Catalyst. Petroleum Chemistry 2017. Vol. 57(7), P. 618-629.

9. Tang X.D., Chen X.D., Li J.J., Deng L.Y., Liang G.J. Experimental Study on Homogeneous Catalytic Upgrading of Heavy Oil. Petroleum Chemistry 2017. Vol. 57(12), P. 1018-1023.

10. Kondrasheva N.K, Kondrashev D.O., Rudko V.A., Shaidulina A.A. Effect of hydrocarbon composition on quality and operating characteristics of middle distillate fractions and low-viscosity marine fuels. Chemistry and technology of fuels and oils 2017. Vol. 53(2), P. 163-172.

11. Petrukhina N.N., Maksimov A.A. Physicochemical properties and performance characteristics of naphthenoaromatic jet and diesel fuels obtained by hydrotreating of highly aromatic fractions. Petroleum chemistry 2018. Vol. 58(5), P. 347-374. 